fluid and clear, the cobalt borate ball partly dissipated, and, on cooling, the surface of the bead presenting a pink appearance, evidently caused by projected particles of soda, volatilised per se.

6. It would thus seem that the blowpipe is even a more delicate analytical weapon than the spectroscope, for it distinguishes between two flames exhibiting D.line spectra only, which spectrum analysis does not.

March 6

\section{The Screw-Propeller in Nature}

Now that the question of the best form of the screw as a propeller has become of such importance it is interesting to note what Nature has done in this direction.

The seed of the ash (Fraxinus excelsior) is provided with a wing very delicately twisted, and, when the seed falls, the action of the air upon this screw-like wing causes it to revolve rapidly. The result is that the seed is kept suspended in the air for a comparatively long time, and is wafted by the slighrest breeze to a considerable distance from the parent tree. I do not know that this peculiarity is referred to in any botanical work, but it very beautifully fulfils the object which characterises more com. pletely the lighter-winged seeds, viz., the dispersion of the seed beyond the limits of the plant or tree which bears it.

I am not by any means sure that the screw on the ash seed will not by its orvin action, independently of any wind, work itself away, in its fall, from the perpendicular line. But, when the wind blows strongly--and it takes a strong wind to blow the seeds off at all-their range is very extensive.

The seeds hang stubbornly to the tree through the winter inonths, reserving themselves for the March gales, of which the wind-fertilising plants avail themselves so largely.

I should much like to know if any of your readers have ob. served this screw and studied its pitch, and it would be very remarkable should it prove that the pitch of this natural screw is the one which will give the most power to the propeller of a steamer.

The seeds of the maple and the sycamore have somewhat similar appendages, but the screw is, in neither case, so marked. If anyone, at this season, will throw up a stick at the seed clusters of ash, maple, or sycamore, he will find the seeds come fluttering to the ground like a cloud of butterfies and alighting quite as softly on the ground.

Feb. 15

ALFRED George, ReishaW

\section{The Migration of Species}

IN NATURE, vol. xii. p. 86, I read a communfation signed "W. L. Distant," in which the writer states that seargoing ships were frequently visited by both birds and insects.

In confirmation of this fact, I can mention from my own observation two instances of birds visiting ships in which I was making the homeward voyage from the West Indies, and one instance on a voyage to $\mathrm{New}$ Zealand, in which the visitor was a butterfly.

In the first case, the ship being off the Spanish coast, but no: in sight of land, a very handsome bird came on board. It was a species of dove, blue being the principal colour, with darker markings. Some of the seamen called it a Spanish dove. It was caged and taken home by one of the passengers.

In the second case, being in the neighbourhood of Bermuda, a large flight of a species of swailow settled on the vessel. These poor birds were in a very exhausted condition, and numbers of them were captured by a large cat belonging to the ship. The survivors continued their passage at daybreak next morning.

In the year $186-$, on a voyage to New Zealand, we were one morning visited by a butterfy, there being at the time a light breaze blowing. My sons made great efforts to capture this interesting stranger, but unfortunately without success, as it fluttered overbostrd, and was soon lost to sight in the hollows of the wayes, They, however, got sufficiently near to ascertain it to be a true butterfy. The colour consisted of various shades of rich orange brown, and the margins of the wings were deeply indented.

I made careful inquiries of the officers of the ship as to the proximity of land, and was informed that the nearest was the rock of St. Paul's, then fully two hundred miles distant

Patea, Taranaki, New Zealand, Nov, 18, I875

\section{The Three Kingdoms of Nature}

SOME children were playing at a game called "The Kingdoms," which consists in the mention of various substances, and asking if they belong to the animal, vegetabie, or mineral kingdoms. One little girl mentioned "water," and the com. pany were puzzled as to which kingdom it should be assigned. Is there a sub-aerrial or gaseous kingdom? Will you kindly enlighten the members of our NURSERY March 4

\section{OUR ASTRONOMICAL COLUMN}

The Variable Star, $\beta$ Persei (Algol). - Herr Julius Schmidt, Director of the Observatory at Athens, publishes in the Astronomische Nachrichten the results of observations on the times of minima of this variable star, extending from August 184.6 to November 1875. The epochs are given in Paris mean time with correction for the light-equation. The probable error of a single determination of the time of minimum from 183 observations by Schmidt is $\pm 80^{\circ}$ minutes ; fifty observations of Argelander gave a probable error of $\pm 6^{\circ} \circ$ minutes, and fiftyfive observations of Schönfeld, one of \pm 4.6 minutes, showing by a mean of the 288 observations a probable error of $\pm 7 \circ 0$ minutes. The period assumed by Schmidt in the discussion of his Algol observations between I8401875 is $2 \mathrm{~d}$. $20 \mathrm{~h} .48 \mathrm{~m} .53^{\circ} 6 \mathrm{~s}$.

Some interesting details respecting this star are found in Schönfeld's "Der lichtwandel des Sterns Algol im Perseus" (Mannheim, 1870), His comparison stars and their relative assumed brightnesses were :-

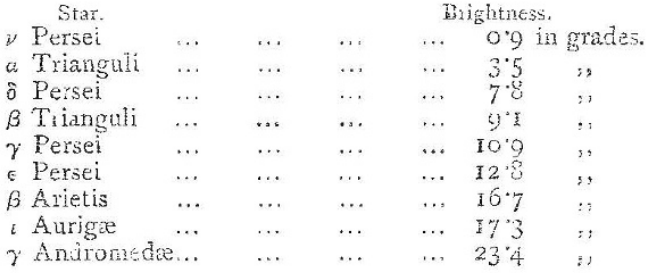

The following, extracted from the more extensive table given by Schönfeld in his treatise, will indicate the law of variation as derived from the light curve :- -

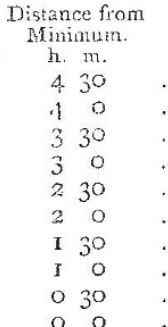

\begin{tabular}{|c|c|c|c|c|}
\hline & \multicolumn{4}{|c|}{ Brightness. } \\
\hline$\cdots$ & $\begin{array}{l}\text { Beform. } \\
20^{\circ} 7\end{array}$ & $\ldots$ & $\ldots$ & $\begin{array}{l}\text { Afrer } \\
20.8\end{array}$ \\
\hline$\ldots$ & $20 \%$ & $\ldots$ & $\ldots$ & $20 \cdot 2$ \\
\hline$\ldots$ & 196 & $\ldots$ & $\ldots$ & $19 \cdot 2$ \\
\hline$\ldots$ & $15 \cdot 7$ & $\ldots$ & $\ldots$ & $17 \%$ \\
\hline$\ldots$ & 174 & $\ldots$ & $\ldots$ & $15 \cdot 8$ \\
\hline$\ldots$ & 153 & $\ldots$ & $\ldots$ & 13.2 \\
\hline$\ldots$ & $12 \cdot I$ & $\ldots$ & $\ldots$ & 9.8 \\
\hline$\ldots$ & $8 \cdot 5$ & $\ldots$ & $\ldots$ & $7 \cdot 6$ \\
\hline$\ldots$ & $6 \cdot 3$ & $\ldots$ & $\ldots$ & $6 \cdot 2$ \\
\hline$\ldots$ & 5.0 & $\ldots$ & $\ldots$ & $5 \cdot 6$ \\
\hline
\end{tabular}

The most probable period over which the variation extends is $9 \frac{1}{4}$ hours, and the minimum lies very nearly in the middle of the same. The most perceptible diminution of brightness occurs $1 \mathrm{~h} .26 \mathrm{~m}$. before the minimum, when the star is somewhat fainter than the mean of $\gamma$ and $\epsilon$ Persei, and the most perceptible augmentation when the star arrives at nearly the same degree of brightness, but $\mathrm{rh} .47 \mathrm{~m}$. after minimum. In this phase it is hardly fainter than the mean of $\delta$ Persei and a Trianguli. Schonfeld states that to his eye the variation of Algol is included between the magnitudes 2.2 and 3.7 ; he considers $\gamma$ Andromedæ an average star of the second magnitude, $\delta$ Persei 3.5 , a Trianguli about $3 . \mathrm{I}$, and $\nu$ Persei $4 . \mathrm{I}$.

For elements of Algol we may adopt at present the following, derived from Schönfeld's last catalogue. First minimum of $1876 \ldots$ January 2.23233 Greenwich mean time ; period 2.867288 . 
CONJUNCTION OF JUPITER AND $\beta$ SCORPIr.-Mr. J. Birmingham, Millbrook, Tuam, writes as follows with reference to the near approach of Jupiter to the bright star $\beta$ Scorpii on the morning of Feb. 28,--" The weather prevented any observation until $19 \mathrm{~h} .25 \mathrm{~m}$. Greenwich M.T., when the western limb of Jupiter had nearly, but scarcely quite, reached the R.A. of the star. The micrometer-wire through the star then just grazed the northern edge of the planet, and so closely that it could not be said for certain that there had not been actual contact. Clouds coming on again soon put an end to the observation." Allusion was lately made to the above phenomenon in this column.

NOTE ON BIELA'S COMET.-It will be remembered that when, on the appearance of Biela's Comet in 1805 , the similarity of elements to those of the comet of 1772 had been remarked, it was pointed out by Gauss that the differences between the orbits, particularly the diminution of the inclination, could not be accounted for except on the supposition that in the interval the comet had undergone perturbations from one of the larger planets, and the necessary proximity could only have been consistent with the assumption that several revolutions had been performed in the interval between 1772 and 1805 , as on the next observation of the comet in the spring of 1826 was proved to have been the case.

If we adopt the elements for 1772 assigned by the late Prof. Hubbard of Washington in his masterly investigation on the motion of this comet, we shall find the follow$\mathrm{ng}$ distances from the orbit of the planet Jupiter :-

\begin{tabular}{rrrrcccc} 
True Anomaly, & \multicolumn{9}{c}{ Radius vector. } & & Distance. \\
$+156^{\circ} \mathrm{o}^{\prime}$ & $\ldots$ & $\ldots$ & 5.029 & $\ldots$ & $\ldots$ & 0.316 \\
157 & 30 & $\ldots$ & $\ldots$ & 5.143 & $\ldots$ & $\ldots$ & 0.281 \\
158 & 0 & $\ldots$ & $\ldots$ & 5.180 & $\ldots$ & $\ldots$ & 0.283 \\
+160 & 0 & $\ldots$ & $\ldots$ & 5.327 & $\ldots$ & $\ldots$ & 0.344
\end{tabular}

A true anomaly of $157^{\circ} 30^{\prime}$ corresponds to 645.5 days after a perihelion passage, and the comet would arrive at this point of its orbit, which may be taken as that of nearest proximity to the orbit of Jupiter about I794'2 I, while the planet would be in the same longitude about $1794^{\circ} 43$, and it thus appears that it was in the spring of the year 1794 that the very material changes in the elements of the comet's orbit were caused by the attraction of Jupiter. Another near approach of the two bodies would appear to have taken place towards the end of the year 1746 .

\section{THE NEW GERMAN SCIENTIFIC EXPEDI- TION TO THE OBI}

THE Expedition to Northern Siberia, fitted out by the "Verein für die Deutsche Nordpolarfahrt in Bremen "- the same Society which sent out the Second German North Polar Expedition, and published the excellent account of its results--left Bremen last week. The attention of the Council of the Society having been called to the immense unexplored area between the Jenisei and the $\mathrm{Obi}$, it was resolved, as there were not sufficient funds for a naval expedition this year, to send out a small zoological and ethnographical expedition overland to the Obi, which appeared to be less known than the Jenisei. In this they received the warm support of the highest scientific authorities at St. Petersburg who were asked for advice on the subject. Dr. Otto Finsch, Director of the Zoological Museum at Bremen, was appointed leader of the expedition, and Dr. Brehm, the well-known author of "Das Thierleben" and many other natural history works was selected to accompany him. They were joined by Count Walburg-Zeil-Trauchburg of Stuttgardt, who made an expedition to Spitzbergen in 1870 at his own expense, and who is well acquainted with physics and is a good botanist. Professor Oscar Schmidt of Strasburg, who had likewise intended to go, was unavoidably prevented at the last moment. The route selected is by St. Petersburg and Moscow to Nishni, and thence in sledges viâ Kasan, Perm, Ekaterinenburg and Omsk to Semipalatinsk. Thence a detour will be made, if possible, into the Altai. From Ekaterinenburg they will go to Barnaul and down the Obi to the embouchure of this river. They will return to Germany in the autumn - certainly not without a rich harvest of results.

\section{UNIVERSITY REFORM}

(Communicated.)

THE speech of Lord Salisbury on introducing a bill to reform the University of Oxford, inaugurates a fresh epoch in the history of University reform. The speech nominally referred to Oxford only, but the principles enunciated in it apply equally to both Universities. The defects of the Oxford system, pointed out with such clearness by Lord Salisbury, are also the defects of the Cambridge system, and the remedies to be applied, must, in their broader features, be the same for the two Universities.

Lord Salisbury lays it down as the cardinal point in his scheme of reform that, till the requirements of the University for teaching and research are satisfied, no portion of the funds of the colleges ought to be employed for endowing idle felluwships.

"I do not know," he. says, "that what is available from the whole of the idle fellowships will be required for University purposes, and I do not venture to lay down the principle that no fellowship should exist which would give the holder no educational work, and which should last for a few years. It may be wise to maintain a few of these, limiting the holding of them to a certain number of years, but I do venture to lay down that all the University wants in the shape of museums, libraries, lecture-rooms, and the proper payment of teachers, should be provided for before the subject of furnishing incomes to men who do nothing can be entertained."

The enunciation of such views as these by a Conservative Minister must be hailed by genuine University reformers as a most reassuring sign of the progress of public opinion. Up to the present time such principles as those contained in Lord Salisbury's speech have only been whispered in secret by a few men who have been generally regarded as extreme and unpractical; but it is to be hoped that for the future these principles will form the starting-point of University reform. It is to be regretted that they have not been more distinctly embodied in the Bill presented to Parliament. The indefiniteness of the plan of reform there laid down, and the powers of resistance secured to individual colleges, seriously detract from its efficiency. We trust that these points will be altered in Committee ; otherwise everything will depend on the wisdom, union, and determination of the Commissioners.

Lord Salisbury alluded to the more pressing wants of the University of Oxford, which include a new library, museum, schools, and other permanent structures; and states that for these alone an immediate outlay of $210,000 \%$. is required. In addition to this sum a large yearly income is needed to bring up the staff of University teachers to a suitable standard both in numbers and efficiency. Large as are the wants of Oxford, we believe that those of Cambridge are also very large both as regards permanent buildings and the professoriate. This is not only shown by the report of the Buildings Syndicate of the University of Cambridge, but also by the recent appointment of a Studies Syndicate, which indicates that the present staff of teachers is generally considered inadequate. The above facts are in themselves sufficient to. demonstrate that, if the principles laid down by Lord Salisbury are firmly carried out by the Commissioners it wil 